\title{
PARA EL ESTUDIO DE LA DIÉRESIS MÉTRICA
}

\author{
Por \\ José Domínguez CAPARrós
}

\begin{abstract}
ABIDO es que la teoría general de la sílaba métrica establecida por los manuales de la disciplina distinguen como fenómenos que hay que considerar a la hora de establecer el número de sílabas en un verso: sinalefa (sílaba formada por la unión de dos o más vocales contiguas pertenecientes a palabras distintas: me-taum-bro-saal-va-que-ro-con-ve-ci-no, Góngora), hiato $^{1}$ (si no se da tal unión entre sílabas de palabras distintas: yhu-yó-su-al-maa-la-man-sión-di-cho-sa, Espronceda), sinéresis (unión en una sílaba métrica de vocales contiguas en el interior de palabra que no forman diptongo, es decir, que pertenecen a sílabas gramaticales distintas: de-noc-tur-no-Fae-tónca-rro-zaar-dien-te, Góngora) y diéresis (separación en sílabas distintas de las vocales de un diptongo o triptongo: ${ }^{2}$ quea-bre-vïa-rael-sol-en-u-naes-tre-lla, Góngora).
\end{abstract}

${ }^{1}$ Se ha propuesto el término de dialefa para el hiato métrico (Baehr, 1970: 46-47).

${ }^{2}$ La lista de las combinaciones vocálicas que pueden constituir diptongo o triptongo en español es la siguiente: $a i, a u, e i, e u, o i, o u$ (decrecientes), ia, ie, io, iu, ua, ue, ui, uo (crecientes); iai, iei, uai, uei (Navarro Tomás, 1968: 65-66). Canellada y Madsen (1987: 51) añaden como triptongos las combinaciones: ioi, iau, uau. Éstos serían los diptongos y triptongos normativos. Antonio Quilis (1993: 181) señala que «en el habla aparecen constantemente otros diptongos, no considerados normativamente, aunque de existencia real: son diptongos formados por las vocales medias y baja /e, a, o/». Estas combinaciones en una sola sílaba del verso son las que constituyen la sinéresis métrica. Nebrija (1981: 126-127) trae una lista de doce porque dice que la combinación de $u$ y $o$ (es decir, ou, uo) nunca forman diptongo, como tampoco $a, e, o$ entre sí. Su lista de triptongos es: iai, iei, iиe, uai, uei. 
Hay una diferencia notable entre la terminología de los fenómenos métricos y la que se emplea en gramática descriptiva para hablar de la pronunciación; se trata del empleo del término hiato en gramática para referirse a la pronunciación de vocales contiguas de la misma palabra en sílabas distintas. Lo que en métrica se define como diéresis será considerado hiato en gramática. Por otra parte, al no disponer en métrica de un término general para la pronunciación de vocales contiguas en interior de palabra en sílabas distintas - por ejemplo, la pronunciación $o$ cé-a-no-(lo que en gramática es hiato, pues en métrica hiato se refiere exclusivamente a la separación entre vocales de palabras distintas, es decir, a lo contrario de la sinalefa, y la diéresis se refiere nada más que a los casos en que se deshace un diptongo), ha habido algún tratadista que, como Felipe Robles Dégano (1905), ha propuesto la adopción del término de azeuxis para estos casos de pronunciación de vocales interiores contiguas en sílabas separadas cuando no se trata de diéresis (disolución de diptongo). Este modo de proceder distinto en los análisis de la sílaba métrica y de la sílaba gramatical ilustra muy bien la afirmación de Nebrija en el capítulo de su gramática dedicado al acento:

Canta el poeta, no como el que habla, ni menos como el que canta, mas en una media manera (1981: 137).

La media manera es sin duda el objeto de la teoría métrica, es el espacio teórico en el que se explican fenómenos como el de la diéresis.

Por otra parte, la diferencia de análisis señalada proporciona alguna sorpresa al estudioso de la métrica que justifica una consideración más detenida del asunto. Por decirlo pronto y para situar la cuestión, ¿por qué Navarro Tomás no habla de diéresis en su Métrica española? Se justifica así un somero repaso a la teoría del ilustre metricista sobre la diéresis en diferentes escritos suyos que nos puede servir de base perfecta para plantear los problemas de esta poco atendida cuestión métrica. 
En su imprescindible Manual de pronunciación española, Navarro Tomás no menciona la diéresis en el índice de materias, pero describe, claro está, el fenómeno. ¿Cómo lo hace? Con los conceptos de hiato (pronunciación de dos vocales juntas que no forman diptongo «sino que por tradición gramatical [subrayo] constituyen sílabas distintas») y sinéresis (cuando el «uso consiente que en ciertos casos las vocales que se hallan en hiato se reduzcan a una sola sílaba»). Nótese que lo originario, lo primero, lo normal, es el hiato, y que lo que constituiría una figura, una modificación, es la sinéresis, por eso ésta «suele producir modificaciones importantes en la pronunciación de las vocales a que afecta» (1968: 66). Lo que en métrica llamamos diéresis entra en lo que en el contexto de la explicación de Navarro que estamos comentando se llama hiato, como veremos en algunos ejemplos.

Notemos que al hablar de tradición está introduciendo el componente histórico, que sería el que justificara que viaje pronunciado bja-xe se califique de sinéresis -sería anterior la pronunciación $b i-a-x e$, en hiato, lo que está fundado en su etimología latina: $v i-a-$. Desde el punto de vista del sistema, o de la norma, o desde el que funda el cuadro conceptual que aplicamos a la métrica, podría pensarse en la pronunciación bja-xe como diptongo, más natural, y la pronunciación bi-a-xe como diéresis, destrucción del diptongo. Es decir, al introducir el componente histórico y de uso, se complica el cuadro con el que trabaja la métrica en el terreno de la sílaba. ${ }^{3}$

\footnotetext{
${ }^{3}$ Este hecho es señalado por Canellada y Madsen (1987: 48), cuando dicen: «Sin embargo, la mera distribución de los fonemas no determina si una secuencia de vocales forma sílaba o si estas se distribuyen en diferentes sílabas. En el interior de palabra hay que contar con unas leyes diacrónicas [subrayo] que no podemos introducir en esta descripción sincrónica». Para ejemplo, puede verse el silabeo distinto en: men-guár, ac-tu-ár, mén-guo, ac-tú-o. Rafael Lapesa, en su Historia de la lengua (1965: 299), observa que en el s. XVII, y hasta el Romanticismo, abundan las sinéresis en la literatura; después, sin embargo, una reacción conservadora relega al habla vulgar formas como cáido, extráido, léido, páis, réir (medidos así en Meléndez, Lista o Espronceda). Antes ha señalado las sinéresis en peor, sean, oistes, criada, toreador.
} 
Navarro Tomás considera hiato la pronunciación $b i-a-x e, s u-$ a-be, kru-el, a-ún: y sinéresis, bja-xe, swa-ve, krwel, áun (1968: 67). En métrica, palabras como viaje, suave, cruel, son ejemplo de diéresis cuando tienen la pronunciación que Navarro considera hiato, y no es raro que lleven el signo ortográfico de la diéresis o crema: vïaje, süave, crüel. ${ }^{4}$

La única mención que se hace de la diéresis en su Arte del verso (1959) es para decir que la tendencia general es a evitar los hiatos, que hay influencias de orden gramatical y emocional que se oponen a esta tendencia, y que las vacilaciones «impiden encerrar el tratamiento de estos grupos en reglas simples y precisas. La diéresis o disgregación del diptongo se usa en raras ocasiones» (1959: 14). Porque, lo mismo que hacía en el Manual de pronunciación, sólo usa los términos de hiato y sinéresis para designar la pronunciación de dos vocales contiguas en dos o en una sílaba, respectivamente. Esto lo dice refiriéndose al uso de los poetas, «en condiciones aparentemente análogas», de una u otra forma en palabras como día, ahí, aún, fluido, viuda, huida, ruido. Ejemplifica con versos concretos formas dobles de silabeo métrico, que califica de «prosodia inestable», y que ofrece los contrastes: suave / su-ave; cru-el / cruel; oce-ano / oceano; re-al / real; ca-en / caen; a-ún / aún; ru-inas / ruinas; ru-ido / ruido; vi-uda / viuda; sonri-endo / sonriendo (1959: 17-18). No hay, pues, una forma que tenga la primacía, sino que las dos, por ser usadas, son aceptadas como iguales. La prosodia inestable, vacilante, lleva a una terminología que no se encontraría en

\footnotetext{
${ }^{4}$ No es el momento de extendernos en consideraciones sobre el papel que Navarro Tomás concede al uso poético en la pronunciación del español -la lengua poética en español no es distinta del discurso común, la escena o la conversación, aunque por cultismo o arcaísmo hay alguna diferencia en la libertad de silabear o acentuar (1968: 149)- y el importante lugar que los ejemplos tomados de la poesía tienen en su descripción. (Véase, por ejemplo, 1968: 149, 155-161). Aunque no es el objeto de este artículo, conviene recordar que Navarro Tomás (1968: 61-63) llama sinéresis la pronunciación en una sílaba del grupo de dos vocales abiertas (em-peo-rar), igual que en métrica; y si se pronuncian en dos sílabas distintas, habla de hiato (em-pe-o-rar), lo que se ha llamado alguna vez azeuxis en métrica, según hemos indicado. Esteban Torre (2000:30-34) considera la diéresis como un caso especial de hiato y un hecho de habla, no transgresión de una ley gramatical. Ejemplifica con ri-en-do, em-bri-a-gar-nos, en versos de Juan Ramón Jiménez.
} 
otros tratadistas de métrica. Hay ejemplos en la lista anterior que Navarro considera hiatos y que otros calificarían de diéresis (su-ave, cru-el, ru-inas, ru-ido, vi-uda, sonri-endo), junto a los hiatos gramaticales que alguna vez en métrica se han llamado azeuxis (oce-ano, re-al, ca-en, a-ún); y de sinéresis que se califican también así (oceano, real, caen, aún), pero otros casos serían simplemente diptongos (suave, cruel, ruinas, ruido, viuda, sonriendo). ${ }^{5}$

El cuadro conceptual del Arte del verso sigue siendo el mismo que el del Manual de pronunciación española, y lo único que añade es la mención de la rareza de la diéresis o disgregación del diptongo. Sus Estudios de fonología española (1966) no añaden otros datos relevantes. Por ejemplo, se refiere a la simplificación en la pronunciación actual del encuentro de vocales que en otras lenguas mantienen su "hiato etimológico", como: coexistir, teologia, violin (1966: 46-47).

El llamativo contraste entre el análisis del fonetista Tomás Navarro Tomás y lo que constituye la doctrina recibida y común en los tratadistas de métrica, y en los editores de poesía que emplean a veces el signo de la diéresis para ayuda de la notación del silabeo métrico, justifica un repaso a la historia de la teoría de la diéresis, las propuestas de notación que se han pensado para estos casos problemáticos de silabeo métrico, y el análisis del quehacer de algunos editores de poesía frente a esta cuestión. A apuntar algo de todo esto se dedica el resto del trabajo.

${ }^{5}$ Rafael Lapesa, de hecho, niega la diéresis, aunque la defina como la escansión de las vocales de un diptongo pronunciándolas con hiato (pi-e-dra, su-er-te, por pie$d r a$, suer-te). Porque si es legítimo elegir entre hiato y diptongo «cuando las dos formas de dicción están admitidas» (como en: $s u$-a-ve, ru-i-na, ru-i-do, y sua-ve, rui-na, ruí-do), «no puede llamarse diéresis al uso de las primeras, muy abundante en poesía» (1971: 75). Claro que con su explicación nos está diciendo que se suele llamar diéresis a dichas formas con hiato. En el fondo se censura la pronunciación que se aparta de la natural, y, por tanto, cualquier figura que suponga desviarse de lo normal. Bien claro lo dice:«Tanto para la sinéresis como para la diéresis conviene tener presente que el verso no debe deformar la pronunciación correcta, y que cuantas violencias se cometan contra ella revelan inhabilidad en el poeta» (1971: 75-76). 


\section{La diéresis en la historia de las teorías métricas}

No se trata de hacer la historia de la diéresis, sino de unas calas de la misma en autores como Nebrija, Fernando de Herrera, Rengifo, Caramuel, Bello, Benot y Robles Dégano, que cubren el período que va de fines del siglo XV a principios del xx. Porque, a pesar de lo rápido que pasa E. Díez Echarrí ${ }^{6}$ sobre la cuestión en el siglo de oro, hay materia para una historia bastante más larga, como veremos.

Nebrija, cuando trata de las clases de versos y su número de sílabas (libro II, capítulo VIII), recuerda que debe tenerse en cuenta su doctrina sobre los diptongos (libro I, capítulo VIII). Las vocales se cogen en diphthongo cuando se unen en una sílaba dentro de la palabra -la synalepha es llamada ahogamiento de vocales (1981: 149)-, y se desatan, si se pronuncian en dos sílabas (1981: 126-127). ${ }^{7}$ Algunos ejemplos en que se desata la unión de dos vocales serían casos de lo que hoy llamaríamos diéresis en métrica, pero no utiliza este término. Así, fiel, riel, huida, Luis, donde la $i$ se desata de la $e$, y la $u$ de la $i$, respectivamente (1981: 127). Nebrija, pues, describe el fenómeno de la pronunciación de lo que llamamos diéresis en métrica, aunque en el capítulo de los géneros de versos (libro II, capítulo VIII) no hay ningún ejemplo de diéresis.

Fernando de Herrera tiene mayor interés porque piensa la cuestión desde el punto de vista estrictamente métrico, ya que su objeto de comentario es el verso. Además, por su constante atención a los aspectos gráficos en la edición de Garcilaso (1580), ofrece índices del problema que merecen una sistemática consideración. Estudio detallado que no podemos emprender ahora, pero sí apuntamos detalles que indican su preocupación por la forma de solucionar gráficamente algunos problemas del

\footnotetext{
${ }^{6}$ Dice Díez Echarri (1949: 131): «Tocante a la diéresis y a la sinéresis nada encontramos en estos tratadistas que merezca consignarse aquí. Todos los que hablan de estas figuras, es cierto, insisten en que no se abuse de ellas»».

${ }^{7}$ Curiosamente Eduardo Benot emplea una expresión derivada de desatar para indicar la pronunciación separada de las vocales de un diptongo: desate de diptongos (por ejemplo, en 1892, II: 240).
} 
silabeo métrico. Que la terminología de Herrera no se corresponde conceptualmente con la de la teoría métrica española actual, nos lo dice el siguiente párrafo de su comentario al hiato entre las dos primeras sílabas del verso 5 del soneto 13 de Garcilaso (de áspera corteza se cubrían):

No colidió Garci Lasso este verso, porque deshizo aquella sinalefa o compresión que los griegos llaman sinéresis, que es colisión o conjunción con vocales casi enemigas una de otra, que no se puedan contraer juntamente para que el verso no sea hiulco, que dizen los latinos, o laxo por otro nombre [...] I con esta diéresis denota Garci Lasso, apartando aquellas vocales, l'aspereza de los miembros, i la repunancia de la trasformación (1580: 367).

Herrera no tiene inconveniente en aplicar el término de $s i$ néresis a la sinalefa de vocales casi enemigas, ni el de diéresis al hiato entre estas mismas vocales. Pero más interesante es su preocupación por marcar gráficamente los hiatos con un punto encima de cada una de las vocales que no forman sinalefa; o la pronunciación en una sola sílaba de vocales seguidas en el interior de palabra que no formarían diptongo -según Herrera, apegado a la prosodia latina-, con un signo especial parecido a las comillas sobre la primera vocal ( $r^{\prime} i^{\prime} o, v^{\prime} i^{\prime} a$, monosílabos; lluv'i'oso, p'i'adosa, trisílabos):

Danubio r'i'o divino (Canción I, v. 53) que dela v'i'a espantosa atras me torne (Canción IV, v. 131) en lagrimas, como al lluv'í oso viento (Elegía I, v. 23)

I tu tendiendo la p'i'adosa mano (Elegía I, v. 31)

aunque alguna vez va en la segunda vocal:

que nunca di'a' ni noche cessan dellas (Canción III, v. 13)

Lo que Herrera intenta marcar con ese signo gráfico es lo que hoy calificaríamos de sinéresis. Así, cuando ruido es trisílabo no lleva ningún signo especial -compárese con la costumbre de marcar la diéresis con crema sobre la $u$ en poesía- y sí lo lleva cuando es bisílabo: 
la claridad contempla, el ru'i'do siente (Canción IV, v. 98).

Con crema sobre la segunda vocal marca Herrera la diéresis en casos como:

Con luenga esperiëncia sabidores (Elegía I, v. 172)

Si el cielo piädoso i largo diere (Elegía I, v. 295)

Piensas, qu'es otro el fuego, qu'en Oëta (Elegía I, v. 253) ${ }^{8}$

Basten estos ejemplos para mostrar la preocupación de Herrera por los problemas de la sílaba métrica, y el interés que tendría un estudio sistemático de la cuestión en su trabajo editorial.

Rengifo sostiene que cada vocablo tiene tantas sílabas como vocales «sino es que por alguna de las figuras que abaxo diremos, pierda la vocal su fuerça, o se junte con otra y de dos vocales se haga vna sylaba» (1592: 11). La constancia del verso es el ajustarse al número de sílabas exigido, «para lo qual importa mucho saber las figuras que en las medidas de los versos se cometen, y las vocales que o pierden su fuerça, o se contraen, y hazen dipthongos» (1592: 19). En la synalepha no se cuenta la primera vocal; es, pues, la figura en que la vocal pierde su fuerza. La «junta de dos vocales dentro de una misma dicción» para formar una sílaba es la syneresis (ejemplo: Dios, glorioso); es, pues, la figura en que se contraen las vocales, y de ella habla en el capítulo XVII (1592: 20). ${ }^{9}$ No habla Rengifo de diéresis, pero en la explicación de los casos en que se da o no se da la unión de vocales en interior se encuentra algún ejemplo que hoy en métrica se entendería como tal: «Verdad es que algunas vezes,

${ }^{8}$ En el texto, la palabra Oeta lleva un punto sobre la $e$, como el que indica el hiato entre palabras, pero en la llamada del comentario de esta palabra marca crema sobre $e$. Véanse págs. 287 y 331 de la edición de 1580 . Herrera comenta esta palabra diciendo que «aqui esta desatado el diftongo de Oëta, que en nuestra lengua diremos Eta». Nótese que Herrera emplea el mismo término que Nebrija (desatar) para indicar que no hay diptongo, y que se da hiato o diéresis.

${ }^{9}$ La edición del siglo XVIII, ampliada por J. Vicens, añade como ejemplo de sinéresis «aun, Deydad, Prudencia, y las que tienen I, o V, ante E, como: Cielo, Tierra, Viento, Cuerda, Fuego, Muerte. Alvarez cap. 3. de los atributos del verso: Syllaba de gemina facta una, Syneresis esto» (Rengifo, 1759: 25). 
mayormente en el principio de la dicción, pueden la vna y la otra vocal hazer sylaba, como en Triûnfo, diàlogo; y en otras semejantes, que el vso y la experiencia yrà enseñando» (1592: 20). Los diptongos diferenciados por Rengifo son las combinaciones $a u, e u, e y$.

En otros dos momentos encontramos alguna observación que hoy podemos relacionar con el problema de la diéresis, aunque Rengifo, repito, no habla de esta figura. Cuando en el capítulo XVIII trata de las vocales que se hacen líquidas, dice que la vocal $u$ tras $q, g, s$ se hace líquida y no forma sílaba (ejemplo: lengua, aguero, quando, quanto, persuadir). El caso que nos interesa es el de $s+u$ que se da en una palabra tan presente en la cuestión de la diéresis como suave. Aplicando la teoría de Rengifo, sería bisílaba, aunque él no discute el caso concreto de suave. La otra observación que nos interesa es la discusión del verso «Quien quisiere salir victorioso», que «no está constante, o alomenos no está sonoro». La explicación es: «Porque no se haze contracción en, Victorioso, donde la auía de auer, o si se haze falta una sylaba» (1592: 21). Es decir, lo normal sería la pronunciación diptongada rio, que Rengifo llama contracción, y lo anormal es no hacerla, lo que nosotros llamaríamos diéresis, pero no Rengifo, que no emplea este término. El cuadro de Rengifo está, pues, bastante alejado de los conceptos con que la métrica funciona hoy en el análisis de la sílaba métrica en interior de palabra, pues distingue: diptongos $(a u, e u, e y) ;{ }^{10}$ contracción de vocales (en sílaba postónica: glòria, notàrio; si la acentuada es la segunda vocal: victoriòso, otiòso); no contracción ( $\sin$ ningún término concreto: si se acentúa la primera vocal: alegria, dessèo ${ }^{11}$ a principio de palabra algunas veces: triûnfo, diàlogo;

${ }^{10}$ Obsérvese, por contraste, la modernidad de la propuesta de Nebrija, cuya lista de diptongos es mucho más próxima de las listas de la fonética española actual. Rengifo saca sus diptongos de la lista de los latinos. Recordemos que en latín son diptongos los grupos $a e, a u$, oe, y alguna vez ei, eu, ui (Echave-Sustaeta, 1984: 24).

${ }^{11}$ La edición del XVIII observa que estas dos palabras, y otras semejantes, se presentan con sinéresis en poetas de primera magnitud. Trae ejemplo de sinéresis con las palabras deseos, embia (envía). Y observa que está al arbitrio del poeta hacer sílaba con cada una de las vocales en palabras como caer, leer, loar, poeta, real, etc. (1759: 25). 
y otras que enseña el uso)..$^{12}$

La Rhythmica (1665) de Juan Caramuel, tomo II de su obra Primus Calamus, explica en términos mucho más cercanos a nuestro cuadro conceptual el fenómeno de la diéresis. En relación con la sílaba menciona las figuras gramaticales de dissyllabum, diphthongus, diaeresis, synaeresis, syncopa, synaloepha. En el artículo IV describe el disílabo, diptongo, sinéresis, diéresis, figuras que tienen que ver con la sílaba en el interior de la palabra. El dissyllabum -dos vocales inmediatas constituyen dos sílabas-se opone al diphthongus -si las dos vocales forman una sola sílabay describe la realidad de lo que es el hiato gramatical o azeuxis métrica. Las otras dos figuras se definen en función del disílabo y del diptongo, y así la sinéresis es la contracción del disílabo en una sílaba, y la diéresis es la disolución del diptongo en dos sílabas distintas. Los ejemplos españoles que de estas figuras da Caramuel no dejan dudas sobre la coherencia de su sistema y la proximidad al nuestro. Que Caramuel se libera de la servidumbre de la teoría latina y parte de la realidad de la pronunciación del español, nos lo prueba su crítica a Rengifo: no hay sinéresis en Dios, glorioso, como dice Rengifo, porque estas palabras no son por naturaleza bisílaba y tetrasílaba, respectivamente. Además, limita de forma precisa el campo de la sinéresis y la diéresis al verso; sólo se dan estas figuras cuando las exigencias del metro contraen o disuelven dos vocales contiguas. ${ }^{13}$ Los ejemplos y explicaciones de versos españoles no dejan dudas.

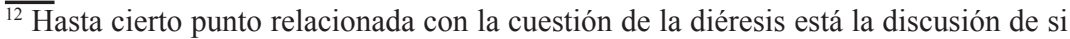
son o no esdrújulas las terminaciones en -io, -ia en sílaba postónica (1592: 276278). Claro que su aparición en versos llanos comunes contradice el deseo de hacerlos esdrújulos por latinismo. Rengifo, demostrando confusión entre lo que hoy llamamos sinéresis y diptongo, argumenta contra quienes dicen que son esdrújulos etéreo, tartáreo, pero no prudencia, audacia, en los siguientes términos: «Pues en el metro ordinario, quando usamos a Ethereo, y a Tartareo, de la misma manera contraemos aquellas dos letras, que quando vsamos a prudencia, y a audacia, etc.» (1592: 277). Pero no puede ignorar que el uso admite ya que se haga diptongo, y «la mala pronunciación de algunos» hace que la vocal que precede a la última se hace «como si fuese consonante» (1592: 278).

${ }^{13}$ En palabras de Caramuel, la sinéresis se da «quando vox ratione carminis, non enim alias caperetur, habet syllabas pauciores, quam deberet. Cui Dieresis opponitur eadem cautela, dissolvit enim syllabam quae alias esset simplex, nisi posceret metrum, vt plures syllabas haberet» $(1665: 24)$. 
Ejemplo de sinéresis se da en el siguiente verso endecasílabo de Pedro Velázquez:

Apolo en el Parnasso desvariaba

en la última palabra, ia forman una sola sílaba, aunque debían ser dos, porque, explica Caramuel, procede de desvarío, donde el acento separa la $i$ y la $o$, y esta separación y acento debe permanecer en los derivados.

Ejemplo de diéresis ofrece la palabra suave -que es bisílabacuando se hace trisílaba, «exigente metri necessitate aut facilitate», en versos de Góngora:

Que en vozes, sino metricas, súáves ${ }^{14}$

Sceptro superíór, fuerça súáve ${ }^{15}$

da otros ejemplos más de Góngora con la palabra suave, y también con el adverbio suavemente:

Súáveménte le trató sevéro

El genio matemático de Juan Caramuel brilla en toda su exposición, tanto a la hora de sintetizar las cuestiones como a la de describir sistemáticamente las posibilidades combinatorias con ejemplos concretos. Así, la concurrencia de dos vocales en interior de palabra es: monosílabo por naturaleza, como en ingenioso (cuatro sílabas), que procede de ingenio (tres sílabas); disílabo por figura, como cuando ingenioso se hace pentasílabo por diéresis; disílabo por naturaleza, como en desafiaron (cinco sílabas), que procede de desafio; y monosílabo por figura, como

${ }^{14}$ Caramuel indica la diéresis con acento agudo sobre cada una de las vocales. En el texto latino de la explicación pone crema sobre la primera vocal: süave. Muy frecuentemente, no siempre, acentúa las dos vocales para indicar que se pronuncian en dos sílabas (sáéta, máéstras, léones, rodéádo, Guadiána, etc... frente a real, sin acento, o séan, véan, con acento en la primera vocal sólo). Aunque no sea estrictamente observada, hay que destacar la voluntad de marcar mediante la grafía el silabeo métrico.

${ }^{15}$ Superiór es tetrasílaba y marca con dos acentos la diéresis. 
cuando desafiaron se hace tetrasílabo por sinéresis (Caramuel, 1665: 25).

Junto a la claridad de los conceptos, hay que destacar algo que nunca se había hecho antes en la teoría métrica española -y que no se volverá a hacer hasta el siglo XIX y principios del XX-: el estudio de las veinticinco posibilidades teóricas de combinación de las cinco vocales en grupos de dos ( $a a, a e, a i, a o, a u ; e a, e e$, $e i, e o, e u ; i a, i e$, etc.) con la descripción del uso poético en la sílaba métrica, centrándose en ejemplos de Góngora. Antes de los estudios de Andrés Bello no se encuentra una mejor muestra de exposición sistemática de la prosodia rítmica. Su objetivo es, según aclara el mismo Caramuel (1665: 25), mostrar a los amantes de las musas (philomusi) qué es lo que se puede y lo que no se puede intentar. En los muchos ejemplos de Góngora dados por Caramuel (1665: 25-33), este se limita a señalar cuándo la concurrencia de dos vocales en interior de palabra constituye una sílaba y cuándo dos, pero no dice, en el caso de formas dobles, cuándo se trata de diéresis y cuándo de sinéresis. Por ejemplo, la palabra día, en Góngora, puede encontrarse como monosílaba y como disílaba; e incluso en un mismo verso, señala Caramuel (1665: 28), aparece con las dos formas: «Peinando dia por dia» (heptasílabo). O en su comentario de la terminación ioso, que es bisílaba (io forman diptongo) y así se encuentra en poesía, pero también los poetas de vez en cuando separan io en dos sílabas (en Góngora, por ejemplo, se encuentra gloriósamente, estudiósa, gloríósa) (Caramuel, 1665: 30). Pues bien, Caramuel no dice cuándo se trata de diéresis o de sinéresis, aunque lógicamente, según explicó al principio, habría que saber cuál es la naturaleza de la sílaba y cuál es su realización por figura.

En Caramuel, pues, hay una definición de diéresis perfectamente aceptable hoy, pero también hay conciencia de fluctuación del uso poético, que él se limita a describir. De ahí sus interesantísimas observaciones, que lógicamente no pueden recogerse ahora y que son dignas de un comentario pormenorizado. ${ }^{16}$

${ }^{16}$ Por dar solamente alguna muestra del interés que puede tener el estudio detallado de Caramuel, no me resisto a traducir el siguiente comentario a Góngora: «En este verso de la estrofa 30, Al diadema de luciente Apolo, hay trece vocales: elide la 
En la obra de Andrés Bello, Principios de la ortología y métrica de la lengua castellana (Santiago de Chile, 1835), es donde queda establecida la mejor teoría de la sílaba métrica, y la descripción más precisa de las condiciones del silabeo métrico. No extraña que sus observaciones sean el punto de partida imprescindible para los desarrollos y discusiones posteriores sobre la cuestión, lo que significa que aún hay que leer a Bello para centrar el asunto. El problema que ahora nos interesa, el de la diéresis, es tratado por Bello en el capítulo II de la tercera parte de su Ortología, titulado De las cantidades en la concurrencia de vocales pertenecientes a una misma dicción. Las definiciones de sinéresis, diéresis, sinalefa, hiato, corresponden al esquema moderno de estos conceptos en teoría métrica. Así, dos vocales llenas $(a, e, o)$ seguidas en una palabra no forman naturalmente diptongo; sin embargo, a los poetas «no les está prohibido contraer alguna vez las dos vocales y formar con ellas un diptongo impropio». Ejemplos de Samaniego (león, monosílabo) y Espronceda (sea, monosílabo). Esta contracción es lo que se llama sinéresis ${ }^{17}$ (1981: 87-88). La definición de diéresis es perfectamente aceptable:

La separación de vocales que normalmente deben pronunciarse en la unidad de tiempo, sonando distintas sílabas, se llama diéresis, y suele señalarse en la escritura con dos puntos, a que se da el mismo nombre, colocados sobre una de las vocales disueltas: glorïoso, süave. La sinéresis no tiene signo alguno (1981: 89).

última de la penúltima palabra por sinalefa: quedan doce. Luego o únanse dia y sepárense cien: o al revés: pues ni pueden unirse al mismo tiempo, ni separarse al mismo tiempo» (Caramuel, 1665: 29). O el análisis del verso de Góngora también, Religioso sea pues beatificado, «en el que o bien la primera palabra debe tener cinco sílabas y la segunda una sola: o bien aquélla cuatro y ésta dos» (Caramuel, 1665: 30). Pero Caramuel aquí mide mal el verso, pues de cualquiera de las dos formas que él propone resultan doce sílabas. Para que el verso tenga once sílabas, religioso tiene que tener cuatro sílabas, y hay que hacer sinéresis en sea y en beatificado. A no ser que se corrija el texto suprimiendo pues y entonces la acentuación del endecasílabo exige el silabeo: religïoso (pentasílabo) y sea (monosílabo). Lo que interesa, de todas formas, es señalar la agudeza con que Caramuel observa las dudas y ambigüedades en el recuento de las sílabas métricas.

${ }^{17}$ Cito a Bello por la edición de la Obras Completas, tomo VI, Caracas, 1981. 
Bello no dice si el signo de la diéresis debe ir sobre la primera o sobre la segunda vocal, y de hecho un poco después encontramos en una misma página diüréticos, vïudez (1981: 100). ${ }^{18}$ En cuanto a la no existencia de signo para la sinéresis, anota Miguel Antonio Caro que en la colección de Poesías de García Tassara «se usó arbitrariamente la crema, o dos puntos, para marcar la sinéresis» (1981: 89). Encontramos, efectivamente, en la edición de las Poesías de Gabriel García y Tassara, hecha por el autor (Madrid, Rivadeneyra, 1872), ejemplos como:

Precipitarse en impetüoso vuelo (endecasílabo) (p. 30)

Fluctüante espejo del naciente dia (endecasílabo) (p. 82)

Y entre aérea, iluminada, ondëante niebla (endecasílabo) (p. 175)

Sobre la lava rëerigir quisieron (endecasílabo) ${ }^{19}$ (p. 198)

${ }^{18}$ Habría que comprobar este detalle en las ediciones aparecidas en vida de Bello. En el prólogo a su edición del Poema del Cid, según la edición de Obras Completas, tomo VII (Caracas, 1986, página 28), emplea Bello la diéresis para indicar el hiato (tanto el gramatical como el métrico que resulta de no hacer sinalefa), en los siguientes ejemplos de versos que considera alejandrinos:

Vio puertas abiertas ë uzos sin estrados

Mezió Mio Cid los hombros e engramëó la tiesta

Comö a la mï alma, yo tanto vos quería

El diä es exido, la noch' queríe entrar;

o en los que considera endecasílabos como:

Yo más non puedo ë amidos lo fago

Pasó por Burgos, al castiellö entraba.

En el caso del último endecasílabo citado habría que comprobar el original, porque si se hace hiato (castiello / entraba) entonces el verso tiene doce sílabas, mientras que con sinalefa sí resulta un endecasílabo. En el primer endecasílabo, $\ddot{e}$ tiene que formar sinalefa con una de las vocales para que el verso tenga once sílabas.

${ }^{19}$ De todas formas, hay otros usos de diéresis que no responden a marca de sinéresis en estas mismas Poesías de García Tassara. Por ejemplo:

«Un gran poëta que aprendió á admirarte» (endecasílabo: poeta, trisílabo) (p. 48) «No hay para ti creëncias ni entusiasmos» (endecasílabo: creencias, trisílabo) (p. 146)

«El vuelo igual de tu alma poësía» (endecasílabo: poesía, tetrasílabo) (p. 169)

Parece que la norma que sigue García de Tassara es marcar la diéresis sobre la primera vocal del grupo cuando indica sinéresis - pronunciación en una sílaba métrica-, y sobre la segunda vocal cuando señala una pronunciación en dos sílabas. Así se ve en dos versos endecasílabos consecutivos en que la misma palabra, Océano, una vez es trisílaba y la otra tetrasílaba:

«Vuelve: tu sombra en el Ocëano impera: 
Trata Bello de encontrar unas reglas que expliquen el uso de la pronunciación de los grupos de dos vocales contiguas en una palabra. La casuística de combinaciones como la de vocal débil $(i, u)$ y vocal llena acentuada $(\dot{a}, e ́, \quad o ́)$, que «forman unas veces diptongo y otras no» (1981: 90), da una idea de la dificultad para determinar cuándo hay que hablar de sinéresis o de diéresis respecto de una pronunciación concreta, sobre todo si esta pronunciación ha cambiado con el tiempo, o se dan las dos formas posibles. Por no alargar esta reseña del pensamiento de Bello, léase lo que dice sobre la unión de vocales débiles $(i, u)$ con acento en la segunda:

Si concurren dos vocales débiles, y es acentuada la segunda, hay variedad en el uso. Unas veces las vocales concurrentes forman diptongo indisoluble, como en fuí, cuita, cuído, descuído (que por su pronunciación moderna pertenecen a esta regla), y otras veces forma diptongo disoluble, o, si se quiere, dos sílabas, que admiten fácilmente la sinéresis, como en ruin, ruina, ruido, viuda (1981: 95).

Se comprenderá que ante situaciones tan inestables -añádase, por ejemplo, que Diana, suave «son arbitrariamente disílabos o trisílabos» (1981: 93)- sea difícil establecer, a partir del uso, cuándo hay que decir que se da una figura (diéresis o sinéresis). Claramente se enuncia el problema en comentarios como el de la combinación de dos vocales llenas en sílaba postónica ( $D a ́$ nao, cesáreo, héroe, plázcaos, temiéndoos), que «forman naturalmente dos sílabas», pero:

Como los poetas hacen casi siempre diptongos las combinaciones inacentuadas de que tratamos (particularmente cuando la penúltima vocal no pertenece a un enclítico, como en plázcaos), pudieran algunos creer que sería mejor invertirla, considerando las tales combinaciones como diptongos naturales que a veces admiten la diéresis por licencia poética. Pero me parece más natural

No hay tempestad: el Oceäno calla» (p. 189).

De todas formas no se trata de un uso sistemático de la diéresis para indicar la pronunciación monosílaba o disílaba del grupo de dos vocales en interior de palabra. 
mirarlas como disílabas por las razones que voy a exponer (1981: 97).

Hay, pues, un no pequeño campo de indecisión que hace prácticamente imposible decir con certeza absoluta siempre y automáticamente, a partir del uso de la pronunciación, cuándo se da una de las dos figuras (sinéresis, diéresis).

Eduardo Benot percibió las dificultades de todas estas definiciones y descripciones; optó entonces por marcar en la escritura, tanto de la prosa como del verso, la pronunciación separada de las vocales contiguas con un punto debajo de la primera vocal, que llama subpunto. Lo que consigue de esta manera es dar las instrucciones para una interpretación prosódica concreta; y si no soluciona los problemas del uso con una norma precisa, al menos en el caso del verso sí ayuda a establecer cómo se debe hacer el silabeo de un verso concreto. Veamos algunos detalles de su interesante propuesta. El punto impreso bajo una vocal «indica que esta vocal no forma diptongo o sinalefa con la siguiente; o bien que, en versificación, no constituiría SÍLABA MÉTRICA con ella». ${ }^{20}$ El subpunto se justifica porque no hay en español un índice ortográfico «que dé el valor de una SÍLABA MÉTRICA a toda vocal que no se una, YA EN DIPTONGO a la vocal inmediata de su mismo vocablo, YA EN SINALEFA a la vocal inicial o a las vocales iniciales del vocablo siguiente». El problema no tiene solución que pueda basarse en reglas -recordemos que A. Bello intentó establecer unas reglas sobre el asunto-:

Pueden darse algunas reglas sobre el particular; pero, por desgracia, ni son tan generales que abarquen todos los casos, ni serían de fácil comprensión para los iliteratos. Además, al que habla o escribe queda mucho de potestativo en esto de unir o separar vocales. Por otra parte, existen voces que tienen más de una prosodia, ya por el uso común i constante de los buenos oradores i poetas, ya por licencias lícitas, o tal vez por abusos más o menos ilegales de

${ }^{20} \mathrm{E}$. Benot sigue esta norma ortográfica en toda su obra. Así en el párrafo que acabamos de transcribir pone un punto bajo la última $e$ de siguiente (no forma sinalefa con la $o$ que sigue) y bajo la última $i$ de constituiría, que escribe sin acento, pues ia aquí es un adiptongo. 
los escritores que no saben salir de un apuro métrico, o no quieren dar al arte toda la corrección que requiere.

Ilustra Benot estas dificultades con ejemplos de versos en que se dan distintas divisiones silábicas de una misma palabra. Así: orgias, bisílabo (Hermosilla), orgía, trisílabo (Espronceda); impios, bisílabo (Herrera), impío, trisílabo (Espronceda); suave, bisílabo (Espronceda), suave, trisílabo (Lista); caos, monosílabo (Escóiquiz), caos, bisílabo (Cienfuegos); cae, bisílabo (Cienfuegos), cae, monosílabo (Lista); roedor, trisílabo (Cienfuegos), roedor, bisílabo (Espronceda). ¿Cómo medir bien a la primera versos como los de Hermosilla, que dicen: «A Ereutalion quité la vida; Ereutalion era i la armadura»? Pues el primer Ereutalion es hexasílabo (se mide: ae-re-u-ta-li-on, con punto bajo la $e$ segunda y bajo la $i$ ), y el segundo es pentasílabo (se mide: $e$ reu-ta-li-on, con subpunto en la $i$ ). La misma dificultad presenta el endecasílabo de Lista, «El crudo altar del druida espantoso», que exige una pronunciación de druida como trisílabo, lo que se indica con un punto bajo la $u$ (Benot, 1892, I: 12-15). Benot hace una detalladísima descripción de la prosodia poética, y recurre continuamente a los ejemplos en verso. Pero no puede reducir a norma todo, a pesar de su rigor de preceptista que no duda en censurar usos concretos de diéresis, pues «en la práctica de la diéresis i de las sinéresis hai mucho de caprichoso i arbitrario, dependiente del uso, i de lo que han hecho o dejado de hacer los versificadores de nota» (1892, II: 79).

No puede extrañar que se den puntos de vista contrarios a la hora de considerar una pronunciación concreta como diéresis o no. Sabemos que Bello ponía como ejemplo de diéresis la palabra süave, aunque después dice que puede ser bisílaba o trisílaba (1981: 89, 93). Pues bien, Benot considera natural la pronunciación trisílaba de $s u$-a-ve y califica de sinéresis la pronunciación bisílaba, con ejemplos de Espronceda (1892, II: 73). ${ }^{21}$

${ }^{21}$ Sin embargo, considera una infracción el desatar el grupo ua en la palabra suavísimos, como hace J. G. González en el siguiente verso endecasílabo: «Esparcís suavísimos olores» (1892, II: 243). 
La polémica está también presente en más de una ocasión. Véase, por ejemplo, la crítica a que somete Benot la teoría de Bello sobre la pronunciación de dos vocales llenas contiguas en sílaba postónica (Dánao, cesáreo, héroe, plázcaos, temiéndoos), que, según el americano, «forman naturalmente dos sílabas» (1981: 96), y no diptongos naturales que a veces admiten la licencia de la diéresis. Esto precisamente es lo que sostiene Benot: dos vocales absorbentes contiguas (es decir, las que Bello llama llenas: $a, e, o)$, si ninguna lleva acento, forman diptongo, y su separación constituye una diéresis («verdaderamente censurable», precisa Benot) (1892, II: 97-98).22

Bello considera natural la pronunciación en dos sílabas de la concurrencia de dos vocales llenas en sílaba anterior al acento (roedor, lealtad, etc...), aunque «la sinéresis es aquí permitida, particularmente si entra en la combinación la vocal e». Pues bien, ya Caro anota que piensa, contra Bello, que la diptongación es natural y la diéresis excepcional (1981: 99). Para Benot es natural la pronunciación trisílaba de poe-sí-a, y es tetrasílaba por diéresis (1892, II: 95).

$\mathrm{Al}$ depender del concepto de diptongo las definiciones de diéresis y sinéresis, el análisis forzosamente dará resultados distintos si se considera el diptongo en el uso, que muestra casos de doble pronunciación. Máxime si a ello se añade como autoridad el uso poético sometido a la regularidad silábica. No hay, pues, unanimidad al hablar de diéresis y sinéresis, aunque sí la haya para entender que cuando se habla de diéresis se habla de un diptongo que se deshace, y cuando se habla de sinéresis se refiere a un hiato que se diptonga. El problema está en lo que cada uno entienda por diptongo, por pronunciación natural de un diptongo. No extraña entonces que, como vimos al principio, Navarro Tomás conceda tan poco lugar a la diéresis en sus descripciones métricas.

Ante este problema de difícil solución, si se parte del uso y no se adopta una convención que sirva de norma -como hace la

${ }^{22}$ Para el resumen del pensamiento de Benot sobre la diéresis y su crítica a Bello, véase 1892, II: 94-103. 
ortografía, por ejemplo, a la hora de legislar sobre la acentuación-, la propuesta de una notación gráfica específica adquiere un relieve especial. Hemos visto la manifestación de esta conciencia en autores del pasado como Herrera o Caramuel. Benot insiste en su utilidad, porque desliga la cuestión de la notación del concepto de diéresis y la hace depender de la pronunciación (silabeo) real del verso. Dice:

De entre los vacíos que presenta nuestra notación ortográfica, ninguno me parece más urgente de llenar que el de la falta de un signo indicador del caso en que dos vocales contiguas son diptongo o triptongo,... para distinguirlo del caso en que cada vocal ocupe el tiempo medio de una sílaba: un índice que nos anuncie cuándo se juntan por sinalefa o quedan desligadas por hiato (1892, I: 252-3).

Se extiende a continuación explicando que la tilde acentual no puede solucionar el problema, para el que él propone el uso del subpunto como sabemos, que «es fácil i práctico; no afea la escritura i salva todos los inconvenientes», y tiene, además, «la ventaja de guiar en la lectura improvisada, sobre todo, cuando un versificador por licencia (casi siempre ilícita) carga insólitamente el acento sobre una vocal donde no se le espera» (1892, I: 258). El subpunto indica la adiptongación de forma más fácil que si se hiciera con la crema (1892, I: 261).23

${ }^{23}$ En el contexto de la discusión comenta Benot algunos intentos de notación del hiato entre vocales contiguas en ediciones de poesía de su época. Menciona el caso de Fernando de Gabriel, quien usó: crema " para indicar que no se hace sinalefa ( $t \ddot{e}$ amo, dë oro); acento cuando se desatan dentro del vocablo, si una de ellas es dominante (día, tenía, pöesía, emplées, deséo, febéa...); acentúa la penúltima sílaba si hay diptongo en la última (pátria, ebúrnea, murmúrio, empíreo). Comenta Benot: «Este sistema, aunque insuficiente, ha servido bastante bien al Autor, mui aficionado al hiato para distinguir rotundamente las sílabas métricas». Sistema análogo, y sin conocer el de F. de Gabriel, es utilizado por la poetisa Blanca de Gassó i Ortiz, en 1870, según Benot; por ejemplo: I Omnipotencia suplicantë eres (1892, I: 254). Otro sistema muy elogiado es el de Guillermo Macpherson en sus traducciones de Shakespeare; usa sistemáticamente crema " sobre la primera vocal de la adiptongación (en el interior de palabra o entre palabras): cöhorte, idioma; con sü áspero temple; de tan distintä índole; no se habrá de crëer cuando con sangre; de Duncan ya, y a sus bëodos jefes; que el turco no ha de ser tan pocö hábil; etc... Claro que cuando en la primera vocal del grupo había acento tenía que poner la crema en la segunda (la llamaban: cumpliälos al punto), y le resultaba 
Las muestras de opiniones distintas sobre la pronunciación natural de vocales contiguas en el interior de palabra pueden aumentarse fácilmente con otros ejemplos sacados de los mismos autores hasta ahora examinados. No es, sin embargo, el espacio de un artículo el lugar para una detenida exposición, que daría lugar a un voluminoso tratado de prosodia. Con todo no puede dejarse de mencionar y destacar el libro de Felipe Robles Dégano, Ortología clásica de la lengua castellana (1905), análisis sistemático de la prosodia rítmica de un amplio corpus de poesía castellana que comprende desde el siglo XVI al XIX. Constituye un tesoro de ejemplos, un muestrario impresionante y bien organizado de la pronunciación en el uso poético. ¿Pero es fiable el uso poético para establecer las leyes de la pronunciación? La respuesta de Robles Dégano es interesante sobre todo por la referencia al problema de las licencias, entre las que hay que incluir la diéresis. Así comenta la cuarta de las dificultades planteadas en la introducción:

Que los poetas, por lo mismo que muchas veces se ven obligados a usar de licencia, no pueden revelarnos ciertamente las leyes ortológicas. Respondo que esta es otra ocurrencia gratuita del adversario, nacida de su ignorancia. Así, pues, niego el supuesto. Supone el adversario que no es posible conocer lo que es licencia y lo que no lo es; y eso alguna vez es verdad: [subrayo] pero es falsísimo que nunca puede conocerse. Cuando, por ejemplo, Herrera (Fernando) dice siempre glorïoso, ímpio, orïente, creo que el lector no negará que eso no es licencia en Herrera, sino indicio bien claro de que así hablaba él; pues cada uno escribe como habla, y habla como piensa. Además, las licencias, de suyo (per se) han de ser menos numerosas que los casos correctos; aunque por alguna circunstancia (per accidens) pueden alguna vez ser más numerosas: y

imposible marcarla en los casos en que las dos vocales llevaban acento (pues tan docto eres tú, / háblale, Horacio). Otro inconveniente del uso de la crema, según Benot, es que crea confusión con su empleo para indicar la pronunciación de $u$ en el grupo gu, lo que llevaría a pensar equivocadamente que palabras como cigüeña, santigüéis son tetrasílabas (ci-gü-e-ña, san-ti-gü-éis ), en lugar de trisílabas. Además, ¿cómo señalar la adiptongación cuando hubiera que marcarla precisamente sobre la $\ddot{u}$ de este grupo, como en el verso de Moreto, "Le argüía en el delito», que según Benot, se mide así: Lear-gü-í-aen-el-de-li-to? (Benot, 1892, I: 254-255). 
esa circunstancia también puede conocerse y determinarse, según verá el lector en esta obra (1905: 8).

Destacamos en el párrafo reproducido el planteamiento del problema del valor del uso poético como norma de pronunciación, y la referencia, casi de pasada, al problema de la determinación de la existencia de licencia, al menos en algún caso. Merece la pena reseñar la terminología y las definiciones de Robles Dégano referidas a la sílaba. Ésta es «el sonido o conjunto de sonidos que se emiten a la vez en cada articulación de la voz» (1905: 33). Entre otras formas, la sílaba puede presentar la de dos vocales formando diptongo, y hasta tres consonantes (pie, pies, treis); y la de tres vocales formando triptongo, y hasta tres consonantes (sa-ciáis, a-griéis). Ahora bien, «cuando hay vocales contiguas ocurren tantas dificultades para determinar el número de sílabas, y son tantos los errores que se van introduciendo en nuestra Ortología, que ésta es la causa principal que me ha impelido a emprender este penoso estudio. [Subrayo] Ahora, prosigamos poniendo las nociones necesarias para adelante». ¿Cuáles son estas nociones? Las de azeuxis, diptongo, sinéresis, diéresis, triptongo. La azeuxis es «la contigüidad de dos vocales que naturalmente no se unen para formar una sílaba», como en Te-ófilo, tra-ído, re-úne, cri-ar. El diptongo es «la unión natural de dos vocales contiguas en una sola sílaba». La sinéresis es «lo contrario de azeuxis: es la unión indebida (o no natural) de dos vocales o tres en una sílaba; v. g., cam-peon en vez de cam-pe-on, cria-do en lugar de cri-a-do, sun-tuo-so en vez de sun-tu-o-so». La diéresis es «la disolución de un diptongo, o la separación indebida y licenciosa de dos vocales, que naturalmente debían formar diptongo»s. Se indica con dos puntos sobre la primera vocal que se llaman crema o diéresis (1905: 34); ejemplos: vïolencia, fiador, trïunfante, acïago, rüinoso. E1 triptongo es «la unión de tres vocales en una sola sílaba», lo que se da en condiciones que especifica seguidamente.

Aparte de los dos puntos de la crema para designar la diéresis, introduce Robles Dégano un signo nuevo en su libro consistente en «una tilde como la de la $\tilde{n}$, para señalar las azeuxis de débil 
átona seguida de vocal tónica» (1905: 35). Este uso es general en todo el texto de su obra, y no sólo en los ejemplos. Así se encuentra en palabras como diéresis, hĩato (35) gratũita (8) guĩon (179) crũel, inflũencia, vĩaje, dĩario, rocĩamos, lĩar, dĩámetro (248).

No es el momento de discutir detalles; sólo destacamos tres puntos. Primero, que la determinación de la figura no siempre es fácil. Por ejemplo, la palabra suntuoso, cuya pronunciación natural para Robles Dégano es tetrasílaba, es ejemplo de sinéresis si se pronuncia trisílaba. Pero, según Bello, la terminación de adjetivos en uoso, en la pronunciación ordinaria hace diptongo el grupo $u o$, y constituye diéresis la pronunciación de palabras como voluptüoso, majestüoso, monstrüosos (Bello, 1981: 92-93). Segundo, se siente el vacío de precisión terminológica, como ilustra la introducción del término azeuxis. Tercero, ve Robles Dégano una necesidad de ampliar los signos ortográficos en relación con algún caso de sonidos contiguos en interior de palabra; además del uso de la diéresis, propone la novedad del signo especial para la no diptongación en los grupos $i, u+$ tónica.

El breve repaso a algunas teorías y discusiones sobre la diéresis nos ilustra sobre el amplio margen de dudas en la identificación de la misma como figura, y sobre la conveniencia de utilizar algún signo gráfico que facilite al receptor la escansión del verso en el caso de la confluencia de sonidos vocálicos. La diéresis ha sido tradicionalmente objeto de atención gráfica en la edición del verso. Hasta el punto de que la doctrina académica legisla, en su Ortografía (1999: 82), el uso de la diéresis o crema en las ediciones de poesía:

En textos poéticos, la diéresis puede usarse colocada sobre la primera vocal de un posible diptongo, para indicar que no existe. De esa forma la palabra a la que afecta y el verso en que se incluye cuentan con una sílaba más. Ejemplos:

El dulce murmurar deste rüido, el mover de los árboles al viento, el suave olor [...]

(Garcilaso de la Vega: Égloga II) 
Nótese la prudente cautela de la Academia en terreno tan resbaladizo: puede usarse, posible diptongo. Es arriesgado precisar más, según lo visto en algunas teorías métricas. Como sabemos, Bello precisamente incluía ruido entre las palabras con diptongo disoluble o con dos sílabas que admiten fácilmente la sinéresis. ${ }^{24}$ Pero también el ejemplo de la Academia merece un comentario. El texto de Garcilaso corresponde a los versos 13-15 de la Égloga II, y si no hubieran cortado por la mitad el verso 15 (que dice: «el suave olor del prado florecido»), este mismo texto serviría de ejemplo para la no existencia de diéresis en la palabra suave, tan presente en las discusiones sobre el asunto.

La misma Real Academia Española, en su Esbozo de una nueva gramática de la lengua española (1978: 43-67), describe la agrupación de vocales y ofrece un magnífico muestrario del uso de hiatos y diptongos teniendo en cuenta distintos registros (vulgar, culto, poético), duplicidad de formas y la variabilidad cronológica en la pronunciación. Queda patente la dificultad del establecimiento de reglas cuya formulación dé cuenta de todos los casos. Tampoco olvida referirse, en el apartado de la ortografía, a la diéresis. Se habla de un uso preceptivo cuando la $u$ suena en los grupos gue, gui, y de un «uso discrecional cuando, por licencia poética o con otro propósito, interese una pronunciación determinada». Da permiso, pues, para anotar con diéresis una pronunciación, sin especificar. En nota a este párrafo sí se refiere al empleo de la diéresis por parte de poetas y editores: quieto (Herrera, ed. 1948), inquïeta, Ocëano (Góngora, ed. 1936). Y comenta:

Es curioso este empleo de la diéresis, en los poetas clásicos, acaso porque no estaban aún fijadas las reglas modernas del acento ortográfico. En el metro regular parece innecesaria o casi innecesaria la diéresis (1978: 150).

${ }^{24} \mathrm{Si}$ se considera naturalmente bisílabo el grupo ui en ruido, no le faltaría razón a A.Gallego Morell para editar sin diéresis, como hace en Garcilaso de la Vega y sus comentaristas (Madrid, Gredos, 1972, p. 171): «El dulce murmurar deste ruido». No se deshace ningún diptongo entonces porque la pronunciación natural de la palabra es trisílaba. 
Como ejemplo pone el caso de las tres formas: pié (pretérito de piar), pie (subjuntivo de piar) y pie (sustantivo), donde el acento indica claramente su carácter bisílabo o monosílabo. Y sigue:

La grafía pie con diéresis, para el subjuntivo, es redundante. Gramáticos y ortólogos modernos, en cambio, hacen uso con frecuencia o sistemáticamente de la diéresis. Algunos distinguen dos formas: (") y ( ) (1978: 151).

La Academia está pensando en Robles Dégano cuando menciona el signo especial, como la tilde de la $\tilde{n}$ que empleaba éste.

Si la teoría está así, no puede extrañar que en la edición de la poesía encontremos las más variadas prácticas, comprensibles e incomprensibles. Vamos a ver algunos ejemplos.

\section{La diéresis en la edición de textos poéticos}

Veamos algunos ejemplos de lo que encontramos en la edición de textos poéticos. Los siguientes están tomados de la de Poesías completas de Fray Luis de León hecha por José Manuel Blecua (1990). La palabra suave puede ser bisílaba o trisílaba, y marca con diéresis la pronunciación trisílaba, como en: «de confección süave sus mexillas» (p. 72, v. 322). Encontramos, sin embargo, un caso en que suave es bisílabo y lleva diéresis: «y como süave vino bien olía» (p. 76, v. 435). La palabra Sión puede ser bisílaba o monosílaba en el texto, como: «o hijas de Sión, y muy hermosa» (p. 61, v. 18, bisílaba), «Salid, hijas de Sión, salí a porfía» (p. 67, v. 185, monosílaba). ¿Justificaría la doble posibilidad el marcar diéresis en la pronunciación bisílaba, Sión? La palabra preciado o preciada suele ser trisílaba en el texto, y por eso marca con diéresis la pronunciación tetrasílaba en: «tu nariz una torre precïada» (p. 76, v. 415). El mismo grupo iá no lleva diéresis cuando se pronuncia en dos sílabas distintas como en: «que tus pasos guiando descendía» (p. 168, v. 32; guiando, trisílaba); «lo que la en sí fiada» (p. 175, v. 58; fiada, trisílaba). Pero 
sí la lleva en otras ocasiones, como en: «de gotas de la noche, y rocïada» (p. 71, v. 280); «con sed insacïable» (p. 161, v. 78); «tesoro persïano» (p. 171, v. 13); «la nieve ha varïado» (p. 173, v. 3). El grupo ia átono lleva diéresis en: «itanto nos es el cielo pïadoso!» (p. 174, v. 37). La palabra diosa, trisílaba, no lleva diéresis en: «sexto, con la diosa» (p. 168, v. 24); pero el mismo grupo ió sí la lleva en la palabra graciöa, tetrasílaba: «entre todas por bella y gracïosa» (p.74, v. 380). En ruido, trisílaba, marca diéresis: «la del que huye el mundanal rüido» (p. 157, v. 2); pero no en la palabra restituido, pentasílaba: «sin ser restituido» (p. 165, v. 34). En la terminación uoso encontramos dos o tres sílabas, pero no marca diéresis en ningún caso: «el Miño, los que el mar monstruoso cierra» (p. 163, v. 37; monstruoso, trisílaba); «huyo de aqueste mar tempestuoso» (p. 158, v. 25; tempestuoso, pentasílaba). Escribe sin diéresis la palabra cruel, bisílaba: «el árabe cruel, y yere el viento» (p. 179, v. 37). Marca con diéresis la pronunciación bisílaba del grupo oe en: «linalöe con todo lo oloroso» (p. 69, v. 252).

Veamos ahora qué ocurre en la edición de la Obra poética y textos en prosa de Garcilaso de la Vega hecha por Bienvenido Morros (1995). Esta edición ha sido muy apreciada por el público especializado. En lo que se refiere al asunto que nos interesa, advierte el editor:

Se han atendido, asimismo, las necesidades de la escansión señalando las diéresis y sinéresis. En los casos de diéresis se ha empleado el convencional signo de la crema ("), mientras que en los de sinéresis -producidos únicamente en el interior de verso, nunca en rima- se ha suprimido el acento en las palabras afectadas (como, por ejemplo, rio, veia, tenia, etc.) (CXIV-CXV).

El repaso a los sonetos, tal como los edita Bienvenido Morros, no da los siguiente ejemplos de diéresis:

Ya de volver estoy desconfiado (III, 5, p. 14) 25 $^{25}$

${ }^{25}$ Después del texto del verso se indica en números romanos el del soneto, seguidamente el del verso en números arábigos, y por último la página. 
libre el lugar a la desconfianza (IV, 4, p. 15) apenas en el agua resfrïado? (XII, 14, p. 27)

No las francesas armas odiosas (XVI, 1, p. 33)

ni aquel fiero rüido contrahecho (XVI, 6, p. 33)

y el antiguo valor italiano (XXXIII, 6, p. 57)

no bastando su esfuerzo a su crüeza (XXXV, 7, p. 59)

si me quiero tornar para hüiros (XXXVIII, 7, p. 62)

tras süave manjar, recio veneno! (XXXIX, 8, p. 63)

oh crüel monstruo, oh peste de mortales (XXXIX, 10, p. 63) $)^{26}$

El resultado es que el recuento de sílabas métricas queda bastante aclarado con la ayuda de la diéresis. Sólo notamos que quizá habría que marcar diéresis también en la palabra fiar del siguiente verso:

fiar el mal de mí que lo poseo (XII, 8, p. 27) ${ }^{27}$

La comparación de lo que hace Bienvenido Morros con lo que hace algún otro editor de Garcilaso en los sonetos nos ilustrará sobre diferentes actitudes ante el tratamiento de la diéresis. Tomás Navarro Tomás, en su edición de Garcilaso de la Vega, Obras (1973, prólogo de 1935), sólo marca la diéresis en dos de los casos: odïosas (XVI, 1, p. 218), italïano (XXXV, 6, p. 238). Las demás palabras aparecen sin diéresis: desconfiado, desconfianza, fiar, resfriado, ruido, crueza, huiros. No incluye el soneto XXXIX de la edición de B. Morros.

${ }^{26}$ Los dos últimos ejemplos están en el soneto XXXIX, de autenticidad dudosa, donde hay versos con sílabas de más (v. 4: «que, con tu vista, torbas el cielo sereno»; v. 6: «de hermosas flores, que mi esperanza es muerte»), o de menos (v. 12: «Torna ya sin aumentar mis males»).

${ }^{27}$ En cuanto a la sinéresis, el sistema de Bienvenido Morros se aplica cuando el grupo reducido a una sílaba métrica está formado por $i+o, a$, y por eso no se desacentúa la palabra contándoos, que tiene tres sílabas métricas en el verso: «contándoos los amores y las vidas» (XI, 8, p. 26). Notamos un olvido en la supresión del acento en la palabra perdía, con sinéresis en el siguiente verso: «y más del bien que allí perdía muriendo» (XXIX, 7, p. 53). Por otra parte, ¿cómo marcar la sinéresis de veo, con una sílaba métrica en el siguiente verso: «nunca entre sí los veo sino reñidos» (IX, 12, p. 24)? Lo mismo peor, con una sílaba métrica en: «y conozco el mejor y el peor apruebo» (VI, 7, p. 19). Herrera, por ejemplo, marca el signo especial de la sinéresis en la $o$ de peor y en la $e$ de veo (1580: 98 y 119). 
La edición de las Anotaciones a la poesía de Garcilaso, de Fernando de Herrera, hecha por Inoria Pepe y José María Reyes (2001), marca diéresis en los siguientes casos: desconfiado (p. 297), resfrïado (p. 355), odïosas (p. 380), rüido (p. 380), italiano (p. 471), crüeza (p. 465), hüiros (p. 464). Tampoco incluye el soneto que B. Morros edita con el número XXXIX. No marcan diéresis en desconfianza (p. 302), ni en fiar (p. 355). Fernando de Herrera (1580) marca diéresis en la segunda $o$ de odiösas (p. 147) y en ninguna más de las palabras comentadas.

Ejemplos de este tipo para ilustrar lo relativamente subjetivo en el empleo de la diéresis son abundantísimos. Sin duda, el escaso lugar que Navarro Tomás concede a la diéresis en su teoría métrica se corresponde con el uso que hace de ella en la edición de Garcilaso, claramente menor que en las otras dos ediciones modernas comparadas.

Lo único quizá que convendría recomendar, y exigir, es que en una edición se cuide el que la misma palabra aparezca igual cuando tiene la misma escansión. Esto no siempre es así, sino que da la impresión de que se anota la diéresis cuando parece bien, como si solo se midieran los versos a ratos. Algún ejemplo de la edición de los versos de Cervantes hecha por Florencio Sevilla Arroyo y Antonio Rey Hazas (1993-1995). Tomemos la palabra poesía en los endecasílabos del Viaje del Parnaso, donde aparece, en proporción prácticamente igual, tanto en forma de trisílaba (con sinéresis, si consideramos como no diptongo -azeuxis- la combinación oe en sílaba pretónica) como de tetrasílaba (con diéresis si se considera diptongo oe). En la edición mencionada se mezclan las dos consideraciones cuando siempre se edita sin diéresis, pero en dos ocasiones se marca crema sobre la $e$ para indicar que es tetrasílaba:

dulce de la agradable poësía (IV, 32)

y no conoces que es la Poësía (IV, 153)

Lo mejor sería optar por una de las dos posibilidades siempre: o no marcar nunca diéresis, o si se marca en los ejemplos citados hacerlo también -y mejor sobre la primera vocal de grupo- en casos como los siguientes: 
pues de su poesía, al mundo sola (II, 16)

asiste la hermosa Poesía (VI, 263)

anda contino vuestra poesía (VII, 143)

y en medio la divina Poesía (VIII, 53)

la buena, la importante Poesía (VIII, 130)

digo la Poesía verdadera (VIII, 191)

Algún ejemplo de poesía como palabra trisílaba en la misma obra:

en quien vive de asiento la poesía (I, 336)

Desta manera andaba la Poesía (III, 37)

que, habiendo levantado a la Poesía (III, 197) etc.

No es difícil encontrar más ejemplos de incongruencia a la hora de emplear el signo de la diéresis en la edición de las obras completas de Cervantes que estamos comentando. Por ejemplo, el grupo vocálico io en los adjetivos derivados de bríos (brioso, briosa, briosos, briosas) nunca forma diptongo. Estaría justificado quizá no emplear tampoco nunca la diéresis, pues se trataría de su pronunciación normal en Cervantes. Ahora bien, si se quiere orientar al lector para facilitarle la escansión del verso y se emplea la crema, entonces debería hacerse siempre. En casi todos los ejemplos del Viaje del Parnaso se marca la diéresis sobre la $i$, como, por ejemplo:

En esto, vióse [sic] con brïoso paso (III, 76) aunque pequeñas, de ademán brïoso (III, 336) etc.

si bien también hay algún ejemplo de olvido de la crema en esta obra, como:

quedando en cuezo, tan briosa y bella $(\mathrm{V}, 262)$.

Ahora bien, en el resto de las obras estas palabras aparecen sin crema:

los divididos ánimos briosos (Numancia, 378) 
contra cristianos ánimo brioso? (Gallardo español, 1953) ¡Brioso era el villano! (Laberinto de amor, 1553. Heptasílabo) la discreta y la briosa (Pedro de Urdemalas, 2531. Octosílabo) de novillos briosos y cerreros (Elección de los alcaldes, 166) alta de pechos y ademán brioso (Quijote, p. 532)

El examen de otras palabras, en el que ahora no podemos detenernos, nos daría ejemplos de falta de congruencia en el uso de la diéresis. Así, piadoso, puede ser trisílabo o tetrasílabo en Cervantes. Cuando es tetrasílabo suele marcarse crema en la $i$, pero son muchos los casos en que tal marca falta. Compárese «do la nutriz de Eneas pïadoso» (Viaje del Parnaso, III, 146) con «alzó al momento un piadoso grito» (Rufián dichoso, 2197). Ruina, siempre trisílabo, y que unas veces lleva diéresis (sobre la $u$ o sobre la $i$ ), y otras no. En Cervantes Luis es más veces palabra bisílaba que monosílaba; nunca lleva marcada la diéresis. Ruido es trisílaba en Cervantes; los editores indican la diéresis unas veces sobre la $u$, otras sobre la $i$, y otras no la marcan. La palabra cruel, más frecuente como bisílaba que como monosílaba, nos proporciona ejemplos de similares olvidos incongruentes en la indicación gráfica.

\section{Conclusión}

Los términos de hiato y sinalefa, diéresis y diptongo, sinéresis y azeuxis designan los conceptos para la definición del carácter propio de la sílaba métrica. En la teoría del verso de diferentes épocas se ha notado la necesidad de reflejar en la escritura de la poesía el hiato, la diéresis o la sinéresis. De los tres fenómenos, es la diéresis la que ha conseguido una estabilidad que convierte su uso en práctica tradicional, como reconoce la doctrina académica. El margen de libertad dado por la Academia refleja la dificultad del establecimiento de la existencia de la diéresis. Dificultad que procede fundamentalmente de basar su definición en el análisis de la pronunciación en el uso, tan variable, y sobre todo si en tal análisis se incluye también el uso poético. No extrañará entonces que dos pronunciaciones de una misma palabra 
(por ejemplo: su-a-ve, sua-ve) sean calificadas de diéresis y diptongo, o de azeuxis (hiato) y sinéresis, por autores distintos; es decir, cualquier pronunciación será figurada o natural.

Si en la edición de la poesía se quisiera orientar al lector con seguridad en la escansión de las sílabas métricas, habría que adoptar una solución del tipo de la propuesta por Benot. Pero esto supondría crear un nuevo sistema de escritura, como si en los casos de dudas respecto de la pronunciación adoptáramos la escritura del signo del alfabeto fonético. Esto se debe hacer, claro, en las explicaciones técnicas (artículos científicos, tratados, etc.) y es lo que hacemos continuamente cuando representamos un análisis métrico.

De lo que se trata, más bien, es de ver cómo entender el empleo reconocido de la diéresis. En la práctica de la edición de poesía se observan divergencias de un autor a otro, como no puede ser de otra manera dada la dificultad teórica de definición de la diéresis. Pero también se dan incongruencias en la práctica de un mismo editor, y esto sólo se entiende por falta de atención a la métrica. Parece que se marca la diéresis cuando uno se da cuenta, y, si no, no pasa nada.

Hay una posibilidad de llegar al acuerdo; y, puesto que la cuestión es de tipo gráfico, partir de la misma convención que en la Ortografía $(4.2-4.4$, pp. 43 - 46). Es decir, escribiremos diéresis cuando se deshace un diptongo o triptongo gráfico. Esta parece ser la convención que subyace en la práctica del editor de Garcilaso, Bienvenido Morros, y por eso marca la diéresis en desconfiado, hüiros, crüeza, etc.

Esta solución vale para la diéresis y deja igual el problema del hiato métrico y de la sinéresis, que, como sabemos, habían preocupado a poetas y prosodistas. Pero, al menos, introduce algún criterio en asunto tan caótico. 


\section{Referencias bibliográficas}

ANTONIO DE NEBRIJA, E. (1981). Gramática de la lengua castellana. Edición preparada por Antonio Quilis. Madrid: Editora Nacional.

BAEHR, R. (1970). Manual de versificación española. Traducción y adaptación de K. Wagner y F. López Estrada. Madrid: Gredos.

BELLO, A. ( 1981). Principios de la Ortología y Métrica de la lengua castellana y otros escritos, en Obras Completas. VI. Estudios Filológicos. I. Caracas: La Casa de Bello.

BENOT, E. (1892). Prosodia castellana i versificación. Madrid: Juan Muñoz Sánchez, 3 vols. (Hay edic. facsímil al cuidado de Esteban Torre. Sevilla: Anejo I de Rhythmica. Revista Española de Métrica Comparada, 2003.)

BLECUA, J. M. (1990). Edición de Poesías completas, de Fray Luis de León. Madrid: Gredos.

CANELLADA, M. a J.a; MADSEN, J. K. (1987). Pronunciación del español. Lengua hablada y literaria. Madrid: Editorial Castalia.

CARAMUEL, J. (1665). Primus Calamus. Tomus II. Ob oculos exhibens Rhythmicam. Apud Sanctum Angelum della Fratta, ex typographia Episcopali Satrianensi.

DÍEZ ECHARRI, E. (1949). Teorías métricas del siglo de oro. Apuntes para la historia del verso español. Madrid: C.S.I.C., 1970, reimpresión.

DOMÍNGUEZ CAPARRÓS, J. (2000). Métrica española. Madrid: Síntesis, 2. ${ }^{\text {a }}$ ed. -(2001). Diccionario de métrica española. Madrid: Alianza Editorial, 2. ${ }^{\mathrm{a}}$ ed.

ECHAVE-SUSTAETA, J. (1984). Primer libro del verso latino. Barcelona: Ediciones Cefiso.

HERRERA, F. DE (1580). Obras de Garci Lasso de la Vega con anotaciones de Fernando de Herrera. Sevilla: Alonso de la Barrera.

LAPESA, R. (1965). Historia de la lengua española. Madrid: Escelicer, 6. ${ }^{\mathrm{a}}$ ed. -(1971). Introducción a los estudios literarios. Salamanca: Ediciones Anaya, reimpresión.

MORROS, B. (1995). Edición de Obra poética y textos en prosa, de Garcilaso de la Vega. Barcelona: Crítica. (Biblioteca Clásica, 27)

NAVARRO TOMÁS, T. (1956). Métrica española. Reseña histórica y descriptiva. Madrid: Guadarrama, 1972, 3. . ed.

-(1959). Arte del verso. México: Colección Málaga, 1968, 4. ${ }^{\text {a }}$ ed.

- (1966). Estudios de fonología española. New York: Las Américas P. C.

- (1968). Manual de pronunciación española. Madrid: C.S.I.C., 14. ${ }^{\mathrm{a}}$ ed.

-(1973). Edición de Obras, de Garcilaso de la Vega. Madrid: Espasa-Calpe, 10 a ed. (Clásicos Castellanos, 3)

PEPE, I.; REYES, J. M. (2001). Edición de Anotaciones a la poesía de Garcilaso, de Fernando de Herrera. Madrid: Cátedra. (Letras Hispánicas, 516)

QUILIS, A. (1993). Tratado de fonología y fonética españolas. Madrid: Gredos.

REAL ACADEMIA ESPAÑOLA (1978). Esbozo de una nueva gramática de la lengua española. Madrid: Espsa-Calpe.

-(1999). Ortografía de la lengua española. Madrid: Espasa.

RENGIFO [Juan Díaz Rengifo] (1592). Arte poética española. Edición facsímil de la edición de Madrid: Juan de la Cuesta, 1606. Madrid: Ministerio de Educación y Ciencia, 1977. 
-(1759). Arte poética española. Aumentada por Joseph Vicens. Barcelona: María Ángela Martí.

ROBLES DÉGANO, F. (1905). Ortología clásica de la lengua castellana. Madrid: Marceliano Tabarés.

SEVILLA ARROYO, F.; REY HAZAS, A. (1993-1995). Edición de Obra Completa, de Miguel de Cervantes. Alcalá de Henares: Centro de Estudios Cervantinos.

TORRE, E. (2000), Métrica española comparada. Sevilla: Publicaciones de la Universidad de Sevilla, 2002, reimpresión. 